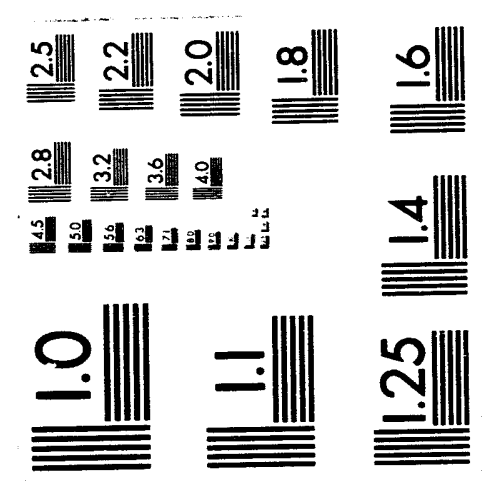



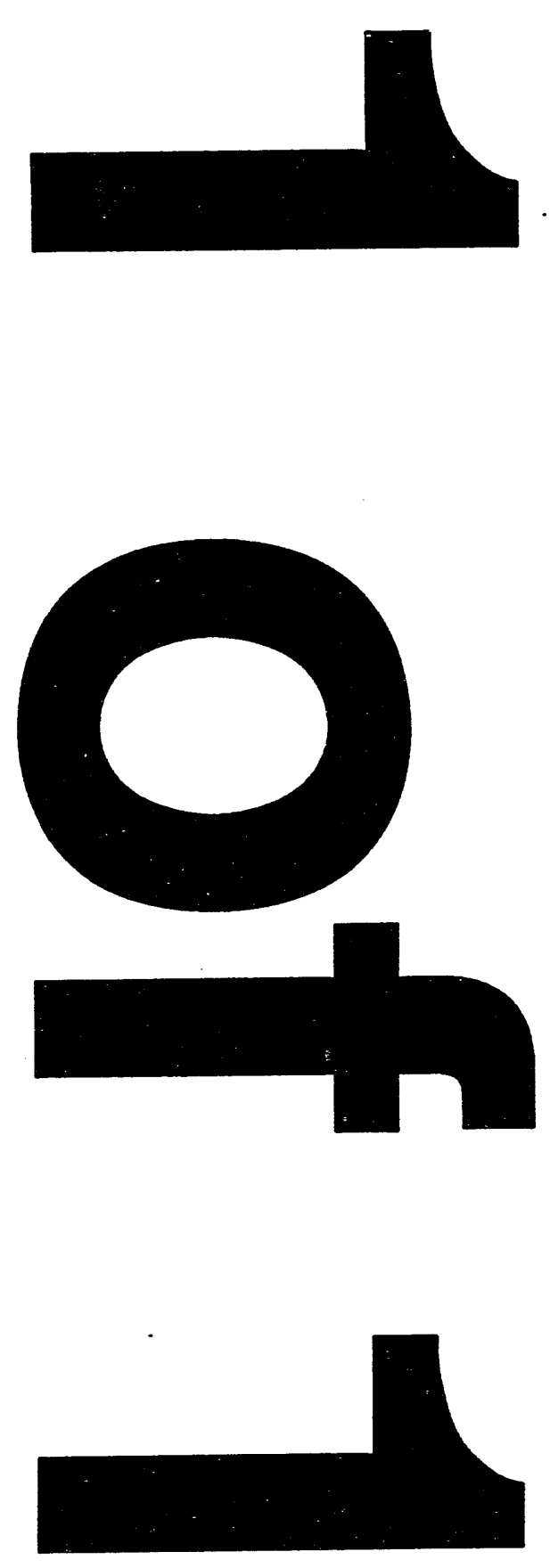
FINAL TECENICAL REPORT

E

September 1, 1991 through December 31, 1992

Project Titled:

Principal Inveotigator:

Other Inveetigatora:

Project Manager:

\section{GASIFIER FEED - TAILOR-MADE FROM ILLINOIS COALS}

Benry P. Ehrlinger, III

Illinole State Geological Survey (ISGS)

J.M. Lytle, R.R. Broet, A.A. L12z10, L.B. Rohlenberger, R.R. Brewer (ISGS); Deetec Energy; Williame Technologies, Inc.; and Illinole Conl Aseociation

Franklin I. Bonea, Illinois Clean Coal Inetitute

\section{ABSTRACT}

The main purpose of this project was to produce a feedstock from preparation plant fines from an Illinols (II) coal that is Ideal for a slurry fed, slagging, entrained-flow coal gasifier. The high-sulfur content and high-Btu value of II coals are particularly advantageous in such a gasifier; preliminary calculations indicate that the increased cost of removing sulfur from the gas from a high-sulfur coal is more than offset by the Increased revenue from the sale of the elemental sulfur; additionaliy the high-Btu IL coal concentrates more energy, Into the slurry of a given coal to water ratio. The Btu is higher not only because of the higher Btu value of the coal but also because IL coal requires less water to producc a pumpable slurry than western coal, $1 . e$., as little as $30-35 \%$ water may be used for II coal as compared to approximately $45 \%$ for most western coals.

This project brought the expertise of four organizations together to perform the various tasks the IIIInols Coal Association (ICA); Destec Energy (DE) : Williams Technologies, Inc. (WTI); and the ISGS. The ICA provided liaison with the State's coal operation, DE provided guidelines and tested slurries for gasification feedstock, WTI provided consultation and testing for high-density slurry pumping, and the ISGS provided slurrles from waste streams from coal washing plants and the analytical work assoclated with them.

During the contract extension, additional coal testing was completed confirming the fact that coal concentrates can be made from plant waste under a varlety of flotation conditions. 33 tests were conducted, ylelding an average of $13326 \mathrm{Btu}$ with $9.6 \%$ ash while recovering $86.0 \%$ of the energy value.

Discussions were conducted with Commonwealth Edison, Franklin County Energy park, and TVA in an effort to have the technology of cleaning fine coal from current plant waste, transportation by sluryy pipeline and gasification by slurry fed, slagging encrained flow gasifler considered in current and future operation plans. Meetings are planned during the first quarter of 1993 to explore possibilities at two of those power generation entities. Although beyond the scope of this contract, ICCI will be advised of any activity developed as a result of this program.

This project is funded by the U. S. Department of Energy (METC) and by the Illinois Department of Energy and Natural Resources as part of their costshared program. 


\section{EXECUTIVE SUANARY}

With the beginnings of coal slurry gasification it was apparent that Illinois (II) coals were natural feedstock candidates. Concentrates of IL coal from either a run-of-mine source or coal washing plant waste can be made to exceed 13000 Btu/pound, have relatively low ash content, and densify to at least $70 \%$ solids while remaining pumpable. The sulfur content is an advantage in that elemental sulfur is a commodity byproduct with a sale value, rather than being an item which must be removed by expensive scrubbing technology which produces a low-cost commodity under the best of conditions, or a voluminous waste under ordinary conditions.

The purpose of this project was to demonstrate that an ideal coal slurry for coal gasification can be generated from waste streams from coal washing plants within the state of IL. This ideal coal slurry contained over 13000 Btu/pound; contained sulfides which can be recovered and sold as elemental sulfur, a low ash content which becomes saleable granulated slag; can be transportable at a high density; and has a reactivity which is desirable as a gasifier feed.

The gasification of coal slurry is a technology which has been proven to be scientifically sound and environmentally effective. The integrated gasification-combined cycle (IGCC) power plants have the capability to achieve heat rates as low as 8200 Btu/KWH (42\% efficient), and are largely waste-free. The products are medium-Btu clean gas, steam, inert granulated slag, and elemental sulfur. The slag and sulfur are marketable; the sulfur has sold for about $\$ 67 /$ ton in the midwest (August 1992). IL coal slurries meet all of the desirable characteristics needed for gasification: 1) it can be concentrated to a grade of greater than $13000 \mathrm{Btu} /$ pound as compared to about $8500 \mathrm{Btu} /$ pound for western coal, 2 ) it can be densified to over $70 \%$ solids and remain pumpable as compared to about $55 \%$ for western coal, and 3) the sulfur is a marketable product in a gasifier rather than a penalty as when IL coal is utilized in conventional combustion.

During 1990, Arch of Illinois (AI) provided a 400 ton lot of washed No. 6 coal for a test at Destec's Plaquemine, LA, 162 net MW gasifier. The purpose was to determine if IL coal presented either an agglomeration froblem or a soot formation problem in a commercial gasifier. The results were very satisfactory; neither concern proved to be a problem.

The methods to provide the slurry were to conduct flotation tests from which Btu recovery, sulfur recovery, and ash rejection were the primary goals. Particle size analyses will be designed to meet the most desirable product for combustion in a slurry-fed gasifier, and rheological studies were to be conducted to determine the optimum and maximum densities of which coal slurry from IL coals may be pumped. 
The work plan was to work with the Illinois Coal Association (ICA), Destec Energy (DE), and Williams Technologies, Inc. (WTI), to identify an ideal gasifier feed based upon chemical analyses, particle size analysis, pulp density, sulfur content, and reactivity. DE has provided guidelines for this requirement. Given these requirements, WTI provided targets with regard to pumpability and offered suggestions for reaching the rheological goals. The ICA served as liaison in reaching coal companies who have waste streams from their coal washing plants from which to conduct test work. The ISGS has obtained samples from the selected companies, and has generated quantities of concentrate to achieve the guidelines for combustibility and pumpability testing.

The ISGS, DE, and WTI held a meeting in Plaquemine, LA, on 9/19/91, where they defined their individual roles: 1) ISGS provides a suite of theoretical products based upon blends of real plant products, 2) DE conducts performance analyses on examples, 3) DOW \& ISGS perform TGA analyses on real products from Powder River (WY) basin and II coal products, and 4) ISGS prepares specific products for evaluation of performance analyses, TGA analyses, and pumpability.

Plant flotation tests have been conducted in which both the fine waste streams from Springfield and Herrin seam coals have been concentrated from about 9000-6000 Btu/pound to over 13000 Btu/pound with recoveries of energy units of over 908 accompanied by a reduction in ash forming minerals to 8-108. This product, along with gravity concentrates, have been tested for pumpability.

During the contract extension, an additional 33 column flotation tests were conducted using coal waste stream material as feed. Concentrates were generated containing ash as low as $5.8 \%$ with 13800 Btu and recoveries in excess of $95 \%$ and as high as 15.78 ash with 12471 Btu by varying flotation conditions. The average of all of the tests was $9.6 \%$ ash, $13326 \mathrm{Btu}$, and $86 \%$ recovery of the energy matter. The purpose was to demonstrate that the chemical analyses described in the earlier test work was reliable, and not produced under narrow span unique conditions.

Exploration tests on reactivity have been conducted on several samples. The University of Illinois' Department of Mechanical and Industrial Engineering Department (Krier, Peters, Hansen, Wu) have conducted a series of tests in their drop tube furnace. The chars from these are being studied, and a longer term (six hour) run will be made to provide sufficient sample for pressurized TGA runs to quantify the reactivity of IL coal as applied to the gasification technology under review.

A number of TGA runs have been made; however, the results appear to be non-reproducible because of the pressurized TGA testing apparatus. 
A project review meeting was held on $2 / 28 / 92$, at the WTI offices and pumping facility in Arizona, to review present work, give guidelines on future work, and to visit the Black Mesa (BM) pipeline installation. Testing of typical samples of flotation concentrate and gravity concentrates, and a weighted composite of the two products was conducted following the proven BM Company's practice. Neither the flotation concentrate by itself, nor the -28 mesh $x 100$ gravity coal concentrate by itself met acceptable pumping standards; however, when the two products were blended 50-50, which is about the weight ratio they would be produced in a typical waste recovery plant, they proved to be nearly ideal, having no settling problems in pumping, could be pumped at about $63 \%$ solids, and required no costly additives while the slurry viscosity was near 190 centipoise. These conditions are very similar to those normally encountered in the BM system.

The results of this work were reported at the ICCI Annual Conference in Urbana, IL, on August 4-6, 1992.

Results of the work described above were sent to the Tennessee Valley Authority, Commonwealth Edison, and the Frankl in County Energy Park administration. The results were then discussed at length in an effort to have the technology of cleaning fine coal from current plant waste, transportation by slurry pipeline, and gasification by slurry fed, slagging, entrained flow gasifier considered in current and future operation plans. Meetings are planned during the first quarter of 1993 to explore possibilities at two of these power generation entities. 
FINAL KANAGEMENT REPORT

September 1, 1991 through December 31, 1992

Project Title: GABIFIER FEED - TAILOR-MNDE FROK IIIINOI8 COAL

Principal Investigator:

Other Investigators:

Project Manager:
Henry P. Ehrlinger, III Illinois state Geological Survey (ISGS)

J.M. Lytle, R. R. Frost, A.A. Lizzio, L.B. Kohlenberger, K.K. Brewer (ISGS); Destec Energy; Williams Technologies, Inc., and Illinois Coal Association Franklin I. Honea, Illinois clean Coal Institute (ICCI)

\section{COMarents}

Approval for a no-cost extension of this project had been granted through $12 / 31 / 92$; reallocation of budget to complete program approved $12 / 17 / 92$, by the ICCI. 
COSTS BY QUARTER - EXHIBIT C

GASIFIER FEED - TAILOR MADE FROM ILLINOIS COALS

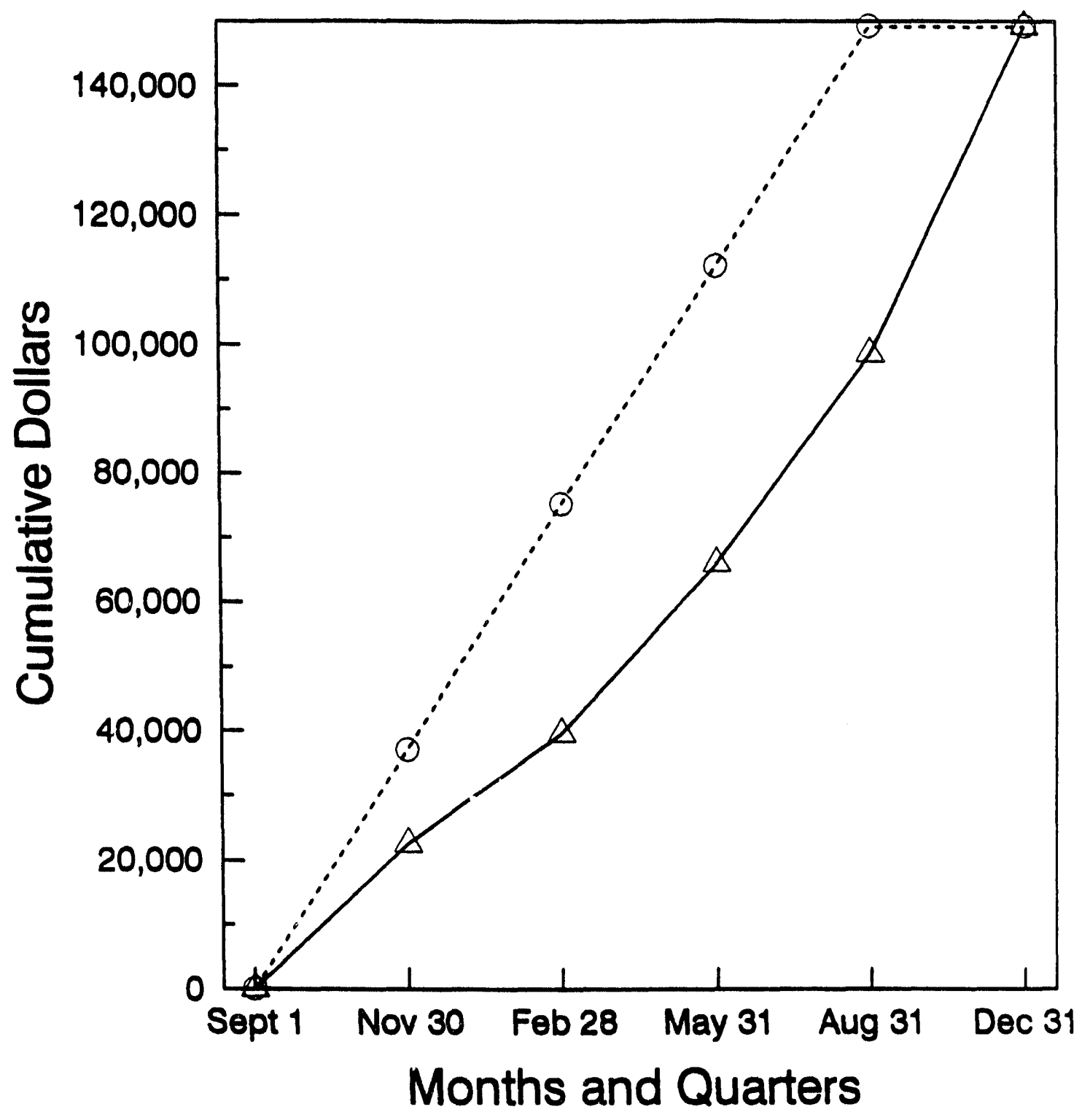

- Projected Expenditures $\quad$....\$149,198

$\triangle$ Actual Expenditures

$\$ 149,198$

Total ICCI Award \$ 149,198 
8CHEDULE OF PROJECT MILESTOMES

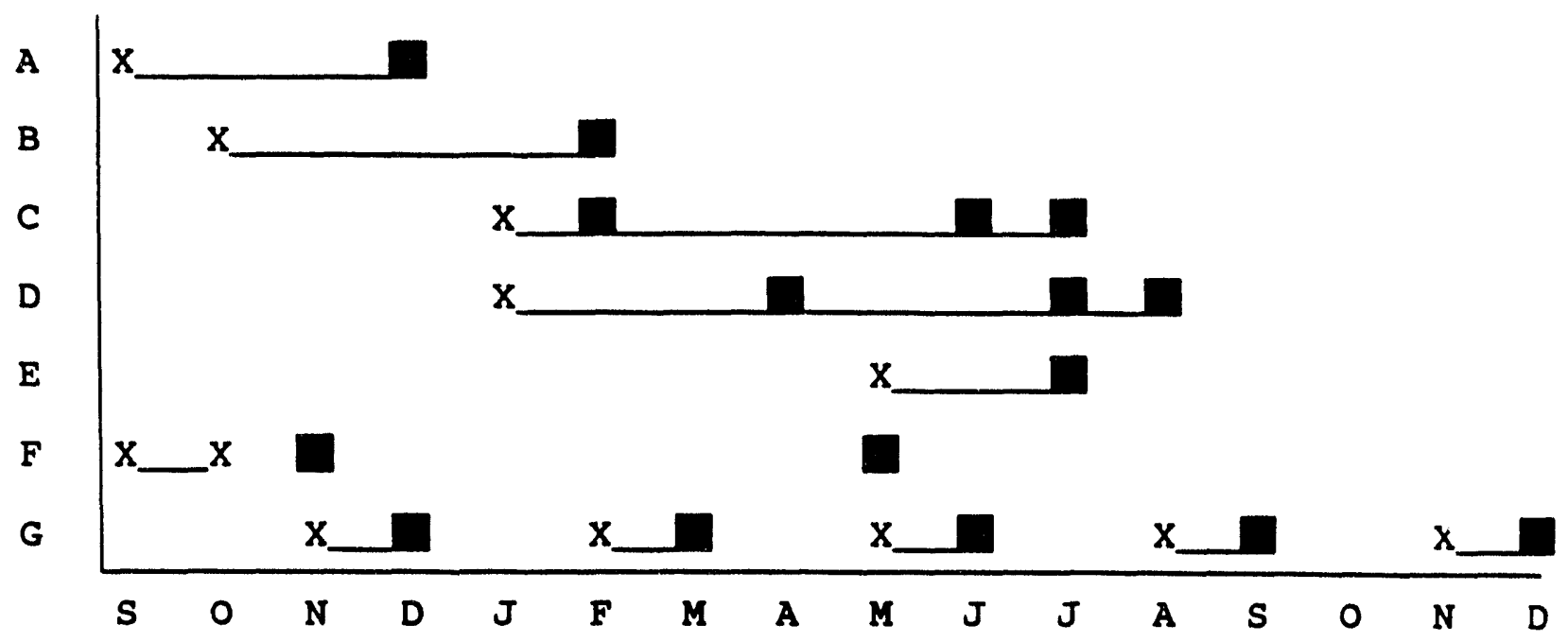

Milestones:
A. Planning Discussions (Task 1)
B. Sample Acquisition and Product Preparation (Task 2 and 3)
C. Gasification Reactivity Testing (Task 4)
D. Rheological Testing (Task 5)
E. Summary Discussions (Task 6)
F. Quality Analyses/Quality Control (Task 7)
G. Quarterly, interim final and final reports 


\section{OBJECTIVE8}

The purpose of this project was to demonstrate that an ideal coal slurry for coal gasification can be generated from waste streams from coal washing plants within the state of IL. This ideal coal slurry will contain over 13000 Btu/pound; will contain sulfides which can be recovered and sold as elemental sulfur, a low ash content which becomes a saleable granulated slag; will be transportable at a high density; and will have a reactivity which is desirable as a gasifier feed.

The principal items to be studied are: 1) methods of concentrating pyrite and decreasing other ash forming minerals into a high grade gasification feed using froth flotation and gravity separation techniques, 2) chemical and particle size analyses of coal slurries, 3) determination of how that slurry can be densified and to what degree of densification is optimum from the pumpability and combustibility analyses, and 4) reactivity studies.

\section{INTRODUCTIOA NMD BACROROUID}

The gasification of coal slurry is a technology which has been proven to be scientifically sound and environmentally effective. The IGCC power plants have the capability to achieve heat rates as low as 8200 Btu/KWH (428 efficiency) as compared to a good pulverized coal plant with pollution controls to limit both sulfur and nitrogen oxide emissions which might have a fuel-to-electricity heat rate as low as $9300 \mathrm{Btu} / \mathrm{KW} / \mathrm{H}$ (37\% efficiency) using hot gas cleaning. The average heat rate for fossil-fueled steam-electric plants from 1985-1989 was $10284 \mathrm{Btu} / \mathrm{KW} / \mathrm{H}$ or $33.18 \%$ thermal efficiency. Additionally, the IGCC plants are waste free; the products are medium-Btu clean gas, steam, inert granulated slag, and elemental sulfur. The slag and sulfur are marketable; the sulfur at about $\$ 67 /$ ton. A pulverized coal plant generates steam, slag in some form, and either $\mathrm{SO}_{\mathrm{x}}+\mathrm{NO}_{\mathrm{x}}$ gases or scrubber sludge, neither of which is desirable. The $\mathrm{CO}_{2}$ generation is a function of plant efficiency thus IGCC would produce significantly less $\mathrm{CO}_{2}$ for the same amount of power generation.

Gasification of coal for the generation of combustible gases which are low in acid rain precursors has been shown to be very viable. DE's Plaquemine, LA, and Texaco's Cool Water, CA, plants have used several coals to prove this technology, both having utilized IL coals on controlled runs.

The coal industry of IL wastes a significant amount of coal as fines from washing plants. A small amount is recovered in three flotation plants and several fine size gravity separation plants treating wash plant waste. An estimate is 
much more than $10,000,000$ tons of recoverable coal is being impounded as waste per year in IL. This coal, when concentrated by gravity or flotation, approaches the size and chemical requirements for gasification. Examples of recent flotation tests are found in Tibles 3-5.

The goal of this research is to determine what the optimum chemical analyses, size analyses, and solids consistency of the slurry for gasification should be, then to tailor-make the raw materials available from IL coal plants into that product.

One consideration which must be explored when selecting a new or different coal for the design coal is the tendency ror agglomeration and soot formation. During 1990, AI gave DE a 400 ton lot of coal which was ground and fired in the second stage of the Plaquemine plant. No adverse effect was noted during that test run.

An additional feature of using IL coal is that it densifies and remains pumpable at over $70 \%$ solids while the western coal will normalize at about at $54 \%$ solids. This means that with II coal concentrate at 13000 Btu/pound, 33 pounds of water $/ M$ Btu must be vaporized while with Western coal at 8500 Btu/pound, 100 pounds of water/M Btu must be vaporized.

Also, while the concentrate from IL coal may have to be ground, the cost of a finishing grind is substantially less that grinding a run-of-mine coal, as is the case with the material provided by western coal.

The coal slurry which is considered in the research is capable of being pumped at high solids using existing pipeline technology. For larger tonnages the use of mine to user pipeline is suggested, for smaller users (less than 2,000,000 tons per year) tanker railway sars or tanker barges are suggested. In either case the rheology of selected samples will be studied.

The short-term goal of this project is to provide coal companies, gasifier users, and transportation specialists with a document which defines the problems of manufacture, utilization, and transport of an idealized tailor-made gasification fuel.

The long-term goal of course is that this work will lead to a stable market for IL coal with a natural or even augmented sulfur content while complying with clean air standards in a more competitive manner.

Because of the enactment of the clean Air Act, much of the IL high-Btu, high-sulfur coal market is in jeopardy. Three alternatives are available to the user of coal: 1) Substitute 
western low-Btu coal for II coal which will meet the mandated sulfur to energy ratios. This can be done either by total substitution, or by blending to a desired endpoint. 2) The installation of scrubbers in their several forms. 3) Adapting power plant practice to take advantage of the high-Btu, highsulfur coal feedstock available with IL coal. IL coal has ideal properties for IGCC which produces power at $42 \%$ efficiency and produces no appreciable pollutants.

The advantages of IL coal over western coal are as follows: II coal has high sulfur which increases the recovery of elemental sulfur, II coal has high-Btu and requires less water to slurry which increases the efficiency of IGCC, and IL coal is near high population centers and requires less cost to transport.

The concept of this project is to provide an idealized slurry feed for gasifier utilization which achieves the following results: 1) is made from a beneficiated wash plant waste product which can be made from existing mined coal, reducing mining cost on a per ton basis to the mining company; 2) the pyritic sulfur content for the coal can be concentrated into the gasifier feed reducing the amount impounded which ultimately will oxidize in the tailing ponds to acidify the area, and which is profitable as a sulfur producer; 3) the quality of the gasifier feed will be optimized with respect to volatile matter, Btu, sulfur content, and ash content to the highest combustible content compatible with the gasifier; and 4) the preferred concentrate will be densified by thickening or centrifuge to provide the highest density, pumpable, rheologically correct slurry to maximize the fixed conditions of the gasifier both technically and cost-wise.

Western coals with their 8500 Etu content will densify to 53568 solids whereas the $13000+$ Btu concentrate, which can be made from waste streams from IL coal, can be densified to over 708 while remaining very pumpable. The fuel therefore would be used to generate gas and steam rather than to vaporize unnecessary Iiquid.

\section{BXPERIMENTAL PROCEDURES}

\section{Task 1. Planning Discussions - All Investigators}

Discussions with other investigators to determine optimum conditions with regard to: 1) physical and chemical properties of the coal; 2) ideal density to satisfy both combustion and rheological factors; 3) desired sulfur content to operate the sulfur recovery unit under its most efficient conditions; and 4) a review of conditions which will determine transportation methods, i.e., tank truck, rail tank car, or pipeline for coal slurry or truck versus rail car for coal filter or centrifuge cake. 
Task 2. Sample Acquisition - ICA/ISGS

Sampling of waste stream products from selected plants within the state to appraise their candidacy for test work. Sampling existing flotation and gravity concentration operations within the state as a reference toward manufacture of ideal or tailor-made gasifier feedstock.

Task 3. Sample Preparation - ISGS

Generation of test size lots required for combustion and/or rheological or filter testing.

Task 4. Gasification Reactivity Testing-ISGS/DE

Gasification reactivity testing in ambient and high pressure TGA apparatus to obtain gasification data under a limited variety of conditions from which samples have been produced in Task 3.

Task 5. Rheological Testing - WTI

Selected samples from Task 3 will be densified, stabilized, and measured by appropriate means to determine pumpability.

\section{Task 6. Summary Discussions - All Investigators}

A final meeting to recommend a product for commercial testing. While not in the scope of this proposal, the long-term goal is to provide the definition of a product which can be commercially manufactured by one or more coal operations for continuous testing or as a plant feed for a commercial sized slurry fed gasifier.

Task 7. OAOC Guidelines on Analytical Procedures and Results - ISGS

QA/QC guideline and procedures will be established during the first quarter and a plan will be filed at the ISGS.

Task 8, Project Management and Technical Reports - ISGS

The ISGS will prepare the reports to the ICCI from the input from all of the participants.

\section{RESOLTB AID DI8CO88ION}

The predicted gasification performance of the baseline ("A") concentrate from wash plant "tailings" and the sample from the Captain Mine are complete. Results of the prediction for these two IL No. 6 coals are compared in Table 2a. Slurry concentration for both samples was taken as $65 \%$. A GE $7 F$ gas 
turbine was used in the evaluation. The ISGS provided DE with a suite of possible feedstocks for appraisal by performance analyses screening which was completed and reported. Table 1 shows the analyses for these samples.

The heat rate (Btu/KwH) of the coal concentrate generated during the program is significantly lower than that derived from western coal, and compares well with steam coal from IL. This brings power plant efficiency from 33-35\% to over $40 \%$.

The ISGS produced plant size quantities of concentrates to be used for purpability testing while conducting test work on a companion project. These were submitted to WTI for a determination of the pumpability of the fine ( -100 mesh) product, the coarse ( -14 mesh $\times 100$ mesh) product, and a blend of the two. The test report indicates that the blend of the coarse and fine products is very pumpable (see attachment).

A meeting was held at the WTI test facility and plant on 2/28/92. Representatives of DE, WTI, ISGS, and ICCI were present. The meeting was to review present work, give guidelines on future work, and to visit the BM pipeline.

\section{COACLOBIONB NMD RECONAELDATIONB}

Using the flotation concentrate made from the waste streams of conventional coal washing plants, a natural feed for slurry fed, slagging, entrained flow gasification is produced. A product in excess of $13000 \mathrm{Btu} /$ pound, less than $98 \mathrm{ash}$ and containing over $90 \%$ of the energy content of the waste stream, is routinely reported. An additional 33 laboratory column tests confirm the reliability of these observations.

This material has a lower heat rate (Btu/KwH) than regular steam coal, or western coal. Heat rate is inversely proportional to plant efficiency. Instead of having 33-35t thermal efficiency normal to many power plants, flotation concentrate fed to an IGCC unit will provide near 42-43\% efficiency, and provide a clean and efficient use for IL coal.

The coal flotation concentrate is a slurry, and the IGCC technology uses a slurry as feed. This saves the cost of more complete dewatering. The gas stream is treated for sulfur removal as elemental sulfur which is a revenue commodity rather than a waste product requiring disposal cost. Thus, the presence of sulfur in the coal is an economic advantage. IGCC is the cleanest and most efficient way to use coal, and IL coal with its high-sulfur content is an ideal feedstock. Thus, Il should push the development of IGCC as quickly as possible to preserve IL coal markets. 
Recent tests have generated a char from IL coals by passing through a drop tube furnace, simulating the reactions upon entry of coal into a gasification chamber. No deleterious products were observed either in the gasification or in the rather unsuccessful high-pressure TGA testing.

As a result of this work, contact has been made with the Tennessee Valley Authority, Commonwealth Edison, and the Franklin County Energy Park. Each of these agencies has requirements which can be answered by the gasification supplied with II coal slurry technology. Planning meetings have been considered with two of the three candidates, and acceptance that this technology is viable has been acknowledged by the third party. 
Table 1. Chemical Analyses of Selected Gasifier Feed slurries

\begin{tabular}{lrrrrrrr} 
& \multicolumn{1}{c}{ A } & \multicolumn{1}{c}{ B } & \multicolumn{1}{c}{ C } & \multicolumn{1}{c}{ D } & \multicolumn{1}{c}{ E } & \multicolumn{1}{c}{ F } & \multicolumn{1}{c}{ G } \\
\cline { 2 - 8 } Ash & 8.30 & 6.80 & 15.70 & 11.60 & 11.50 & 11.60 & 11.40 \\
T/S & 2.19 & 2.58 & 2.77 & 2.42 & 5.08 & 3.79 & 7.43 \\
PY/S & 0.83 & 0.83 & 1.23 & 0.81 & 3.57 & 2.23 & 6.00 \\
O/S & 1.36 & 1.75 & 1.54 & 1.61 & 1.51 & 1.56 & 1.43 \\
Btu & 13420 & 13598 & 12250 & 13150 & 12384 & 12755 & 11706 \\
VM & 30.40 & 30.80 & 27.70 & 29.80 & 28.10 & 28.90 & 26.50 \\
FC & 61.30 & 62.10 & 56.00 & 60.10 & 56.60 & 58.30 & 53.50 \\
H & 4.41 & 4.47 & 4.03 & 4.32 & 4.07 & 4.19 & 3.85 \\
C & 77.61 & 78.64 & 70.84 & 76.05 & 71.61 & 73.76 & 67.70 \\
N & 1.11 & 1.12 & 1.01 & 1.09 & 1.02 & 1.05 & 0.97 \\
O* & 6.40 & 6.39 & 5.65 & 4.52 & 6.72 & 5.61 & 8.65 \\
\hline
\end{tabular}

* oxygen by difference. Since $F e$ is not taken into account, the oxygen contents in samples $E \&$ \& are artificially high. sample $A$ is a true analysis of a sample. Samples B through $G$ are calculated values but probably realistic of what can be produced.

- Products A \& are flotation concentrates made from -100 mesh washing plant waste.

- Products C \& D are flotation concentrates combined with the coal fraction from the spiral separation of -28 mesh $x 100$ mesh waste from coal washing.

- Products E, F\& G are combinations of D above, enriched with varying quantities of high-grade pyrite concentrate from the spirals. 
Results of Destec Gasification Performance Predictions of Washing Plant "Tailings"

Table 2 a.

\begin{tabular}{|c|c|c|c|c|c|c|c|c|c|c|c|}
\hline & $\mathbf{A e h}$ & $T / S$ & Py/s & $0 / 5$ & BTU & ME $\mathbf{z}$ & IC $x$ & B 2 & C $\mathbf{x}$ & $\mathrm{NZ}$ & 02 \\
\hline "A" Wash Plant Waste & 8.3 & 2.19 & 0.83 & 1.36 & 13,420 & 30.4 & 61.3 & 4.41 & 77.61 & 1.11 & 6.40 \\
\hline Captain Mine & 12.54 & 3.59 & $\cdots$ & $-\cdots$ & 12,441 & 39.32 & 48.14 & 4.86 & 69.76 & 1.47 & 7.79 \\
\hline
\end{tabular}

Also included in the tabulation is the ultimate analysis used for the IL No. 6 coal tested at LGTI (2nd stage) from the Captain Mine.

The predicted gasification performance of the baseline ("A") concentrate from wash plant "tailings", and the sample from the Captain Mine are complete. Results of the prediction for these two IL No. 6 coals are compared in Table $2 b$. Slurry concentration for both samples was taken as 65\%. A GE 7F gas turbine was used in the evaluation. 
Table 2b.

\begin{tabular}{|c|c|c|}
\hline COAL & CAPTAIN MINE & "WASTE" CONC. \\
\hline Dry, TPD & $2,296.3$ & $2,044.6$ \\
\hline As Received, TPD & $2,870.3$ & $2,555.7$ \\
\hline Oxygen Required (95\&), TPD & $2,206.8$ & $2,033.1$ \\
\hline slag Product, TPD & 339.8 & 203.6 \\
\hline SYNGAS PROPERTIES & & \\
\hline Moisture Content, Vol. \& & 24.97 & 24.30 \\
\hline Dry Composition, Vol. \& & & \\
\hline $\mathrm{H}_{2}$ & 33.19 & 31.14 \\
\hline CO & 50.09 & 53.25 \\
\hline $\mathrm{CO}_{2}$ & 11.53 & 10.12 \\
\hline $\mathrm{CH}_{4}$ & 2.21 & 2.73 \\
\hline $\mathbf{N}_{2}$ & 1.72 & 1.55 \\
\hline $\mathrm{Ar}^{+}$other & 1.25 & 1.20 \\
\hline HHV: (Btu/Scf) & & \\
\hline Wet & 218.0 & 226.5 \\
\hline Dry & 290.5 & 299.3 \\
\hline NET POWER (MW) & 270.2 & 269.3 \\
\hline HEAT RATE, BTU/KWHR (HHV) & $8,811.5$ & $8,490.2$ \\
\hline
\end{tabular}


In summary, the gasification performance evaluation of the "A" flotation concentrates, from -100 mesh washing plant waste, are shown to compare very favorably with the predicted gasification performance of the IL No. 6 "Captain Mine" coal. Therefore, it is concluded that the "A" baseline material presently being "wasted" from wash plant operations in southwestern II is a viable gasification feedstock when slurried at $63 \%$ solids. The gasification performance evaluation is a process developed by $D E$ for comparing fuels at their operating facility at plaquemine. The formula for this analysis is both proprietary and site specific. 
Table 3

ISGS Coal Plant Test Data Sheet

Test \#: $26 I$

\begin{tabular}{|c|c|c|c|c|c|c|c|c|c|c|c|c|}
\hline Product & ZWt & $\overline{\mathrm{Ash}}$ & T/S & $\frac{\text { Ane1y }}{\text { PTs }}$ & 0/5 & BEu & $\mathrm{SO}_{2}$ & $\overline{\mathrm{Aeh}}$ & $\frac{D}{T / S}$ & $\frac{r \text { lbut } 10}{\text { P/S }}$ & n & BEU \\
\hline Feed & 100.0 & 30.1 & 1.33 & 0.9 & 0.43 & 9915 & 2.68 & 100.0 & 100.0 & 100.0 & 100.0 & 100.0 \\
\hline Conct & 70.92 & 8.4 & 1.31 & 0.71 & 0.6 & 13450 & 1.95 & 19.8 & 69.8 & 55.6 & 100.0 & 96.2 \\
\hline Ta111ng & 29.08 & 83.0 & 1.38 & 1.38 & 0.0 & 1295 & 21.31 & 80.2 & 30.2 & 44.4 & 0.0 & 3.8 \\
\hline
\end{tabular}

Cond1tione:

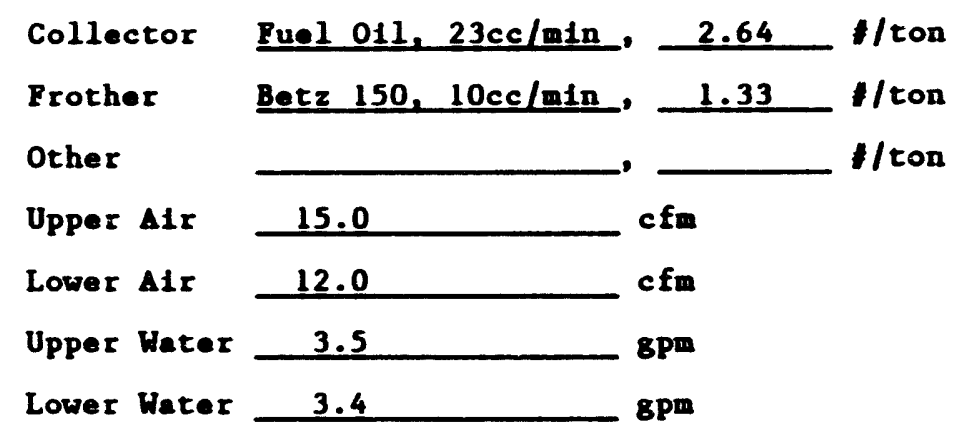

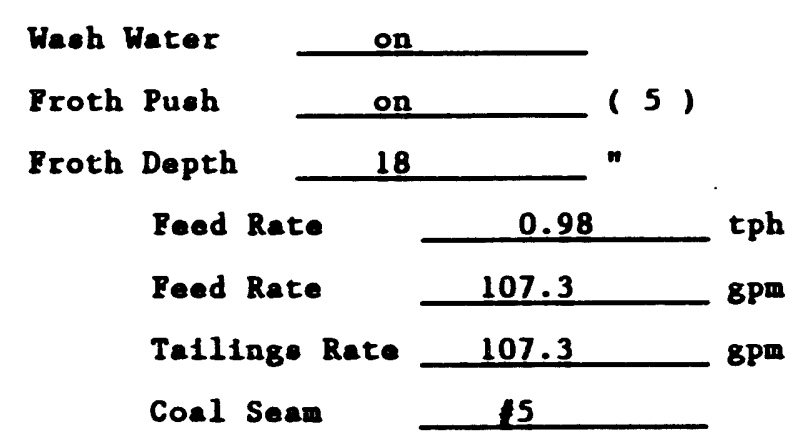


Table 4

IsGS Coal plant Test Data sheet

Test \#: $34 I$

\begin{tabular}{|c|c|c|c|c|c|c|c|c|c|c|c|c|}
\hline \multirow{3}{*}{$\begin{array}{l}\text { Product } \\
\text { Feed }\end{array}$} & \multirow[b]{2}{*}{ 2Wt } & \multicolumn{5}{|c|}{ Anelyeer } & \multirow{2}{*}{${ }_{\mathrm{SO}_{2}}$} & \multicolumn{5}{|c|}{ Dletrfbution } \\
\hline & & Loh & T/S & PTS & $0 / 5$ & btu & & Aeh & T/S & PTS & $0 / 5$ & Btu \\
\hline & 100.0 & 50.1 & 1.81 & 1.29 & 0.52 & 6917 & 5.23 & 100.0 & 100.0 & 100.0 & 100.0 & 100.0 \\
\hline Conct & 44.3 & 9.6 & 2.04 & 0.87 & 1.17 & 13273 & 3.07 & 8.5 & 50.0 & 29.9 & 100.0 & 85.0 \\
\hline Tadling & 55.7 & 82.4 & 1.62 & 1.62 & 0.0 & 1862 & 17.4 & 91.5 & 50.0 & 70.1 & 0.0 & 15.0 \\
\hline
\end{tabular}

Cond1tione:

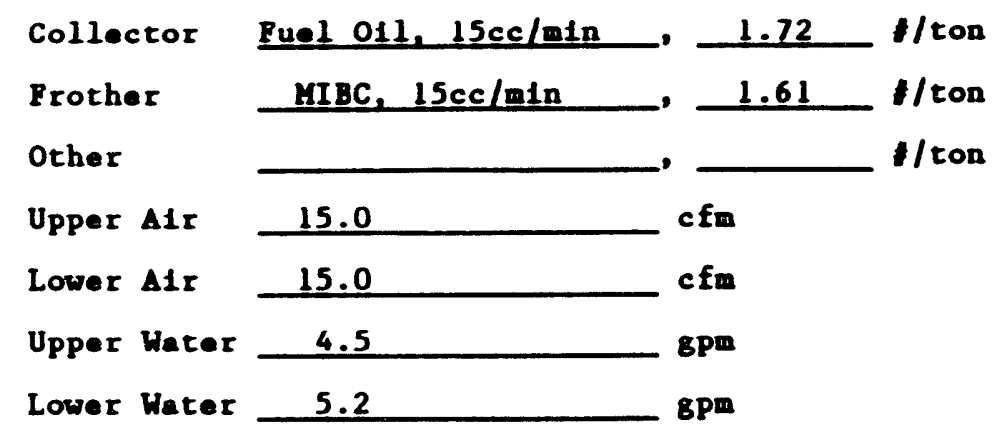

\begin{tabular}{l} 
Waeh Water \\
Eroth Pueh \\
Froth Depth \\
Feed Rate \\
Eeed Rate \\
Tallinge Rate \\
Coal Seam \\
\hline$\frac{110.0}{131.0}$ \\
\hline
\end{tabular}


Table 5

ISGS Coal Plant Test Data Sheet

Test \#: See Below

Date: october 1992

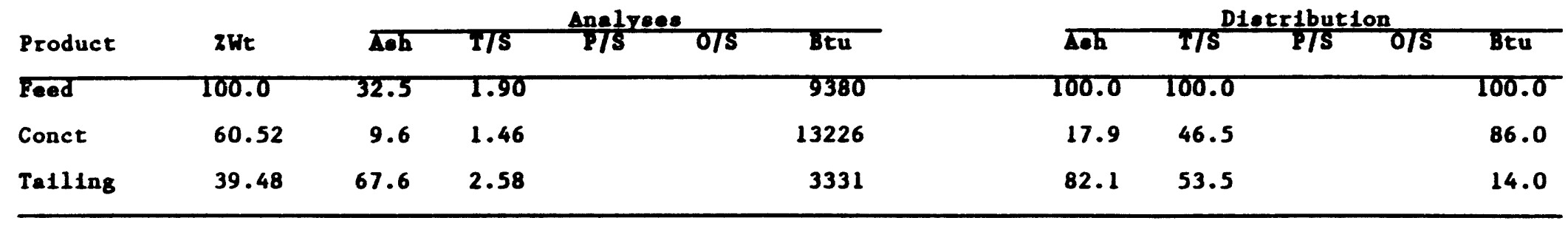

Conditione:
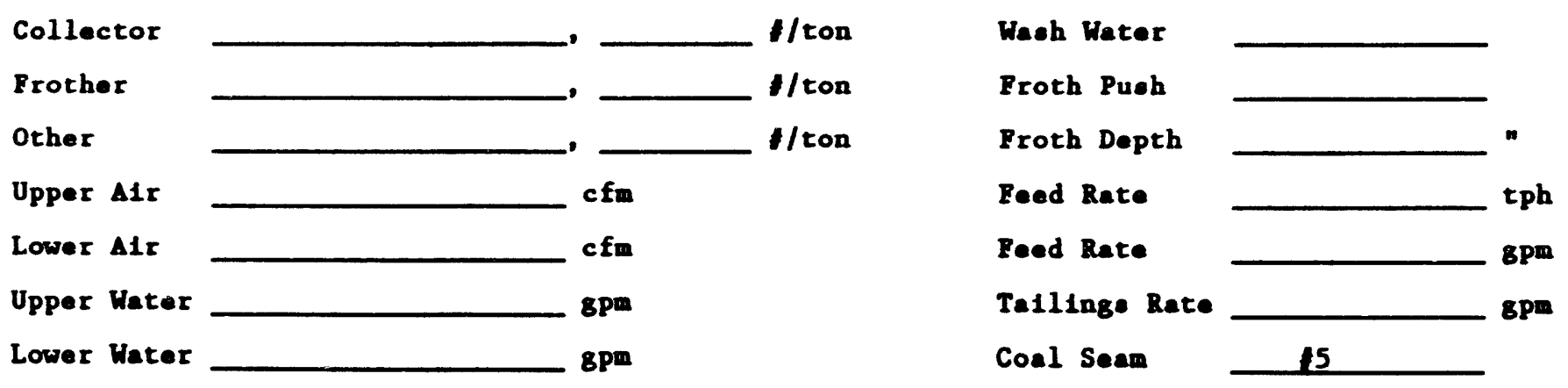

Note: This is a composite of 33 tests on No. 5 coal conducted in laboratory column flotation procedures. The feed rate, the reagent type and rate, and the flotation time varind. This table is included to demonstrate that an acceptable gasifier feed can be provided under a large variety of operating parameters. 


\section{ATTACENGWT}

\section{ILIINOI8 COAL PUMPABILITY TEET PROGRAM REPORT}

WTI received two coal samples from the ISGS in February 1992. These coal samples were collected from a coal cleaning plant in southern II from the same coal seam, but were cleaned by different processes.

The coarse coal sample was from the Bird Centrifuge ( $B C$ ) and was the following particle size distribution:

+14 mesh

$14 \times 28$ mesh

$28 \times 42$ mesh

$42 \times 80$ mesh

$80 \times 170$ mesh

$170 \times 325$ mesh

-325 mesh
\& Retained

$$
14.34
$$

59.24

3.76

6.39

3.92

3.37

9.08
\& $\operatorname{cum}^{\prime} 1$

14.34

73.48

77.24

83.63

87.55

90.92

100.0

The final coal samples was produced from a small, commercialscale Flotation column. The particle size distribution of the fine material was as follows:

\& Retained

+42 mesh

$42 \times 80$ mesh

$80 \times 170$ mesh

$170 \times 325$ mesh

-325 mesh
1.7

2.9

14.5

23.7

57.2
\& $\operatorname{cum} 11$.

1.7

4.6

19.1

42.8

100.0

WTI was requested to determine the pumpability of coal slurries made up of each of these coal samples or a combination of both.

\section{Coarse coal}

WTI attempted to make a pumpable slurry using the BC cake as received. Slurries were mixed at 50, 55, 60, and 65 t weight concentrations. It was determined that there was insufficient 
fines ( -325 mesh) and too much coarse coal (+14 mesh) to produce a stable slurry.

Fine coal.

The fine coal proved to have too much surface area to produce a pumpable slurry at any concentration above 50 solids. The addition of dispersant had little to no effect on mixtures at concentrations up to $55 \%$ solids, which indicates the presence of a very high percentage of -10 micron particle chemicals.

There were two types of dispersant used to determine their effect on reducing the viscosity on the fine coal mixtures. They were: 1) sodium Iigno sulfonate, which added up to 1.08 of coal weight up to solids concentrations of 55 with only slight visible effect and caused hard packing of the settled solids after 12 hours under static conditions, and 2) nonionic surfactant which added up to 1.08 of coal weight of this surfactant to fine coal sample at solids concentrations up to 55t with only slightly better results than with ligno sulfonate. The settled solids did not hard pack after 12 hours.

\section{Conclusions and Recommendations}

The column flotation concentrate has too much extremely fine material to produce a pumpable slurry at solids concentrations in excess of 45-48z without some addition of coal particles in the +325 mesh size range to reduce surface area. (See attached viscosity curve.)

The BC product has too much coarse material to produce a slurry that remains in suspension at reasonable velocities, and would present restart problems in case of emergency shutdown.

After discussion with the PI, H. Ehrlinger, it was discovered that the two products were produced in equal amolints. We then mixed the centrifuge product with the column flotation concentrate in equal parts on a dry coal basis, which produced slurry that is pumpable at concentrations from 50-60t weight.

Slurries at concentrations less than 50 tended to settle quite rapidly, which is caused by the high amount of +14 mesh material. However, slurries of 52-60\% remained in suspension with minimal agitation and did not hard pack under static conditions.

558 concentration slurry produces a viscosity just under $150 \mathrm{cp}$ (see attached viscosity curve) and appears to be quite pumpable with no additives. It should be noted that once a project has been defined and annual throughputs have been 
determined, a comprehensive laboratory program would be required to optimize the slurry on a site specific basis.

The use of chemicals to reduce viscosities is not recommended for this slurry because they are generally ineffective at concentrations under $65 \%$ solids, and usually require a closely controlled particle size distribution to produce the desired rheological characteristic. The cost of chemicals could add approximately $\$ 1.50-\$ 2.50 /$ ton of coal. 


\section{ILLINOIS COAL 50 - 50 Mix Colmn. Float and Bird Conc.}

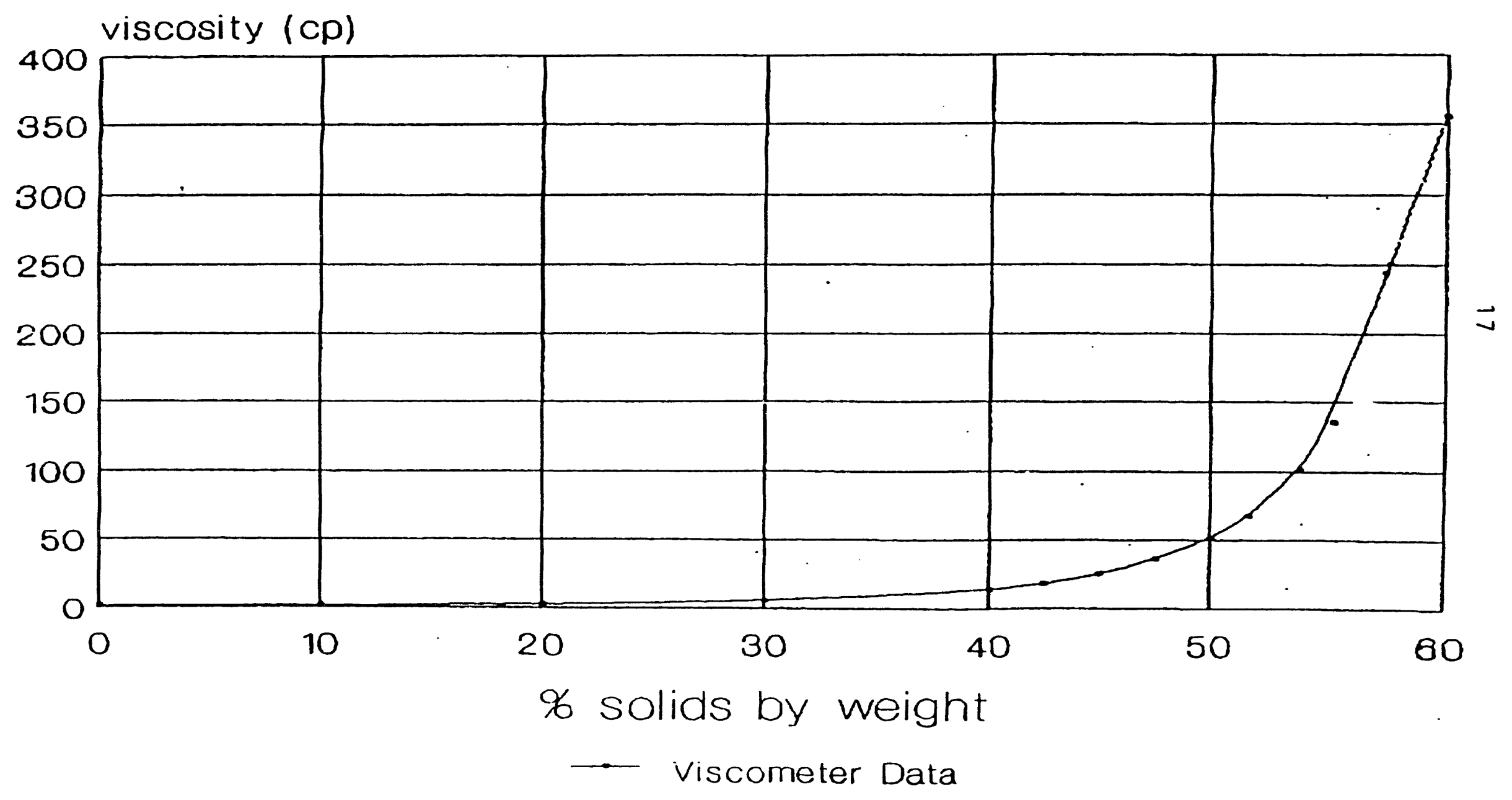



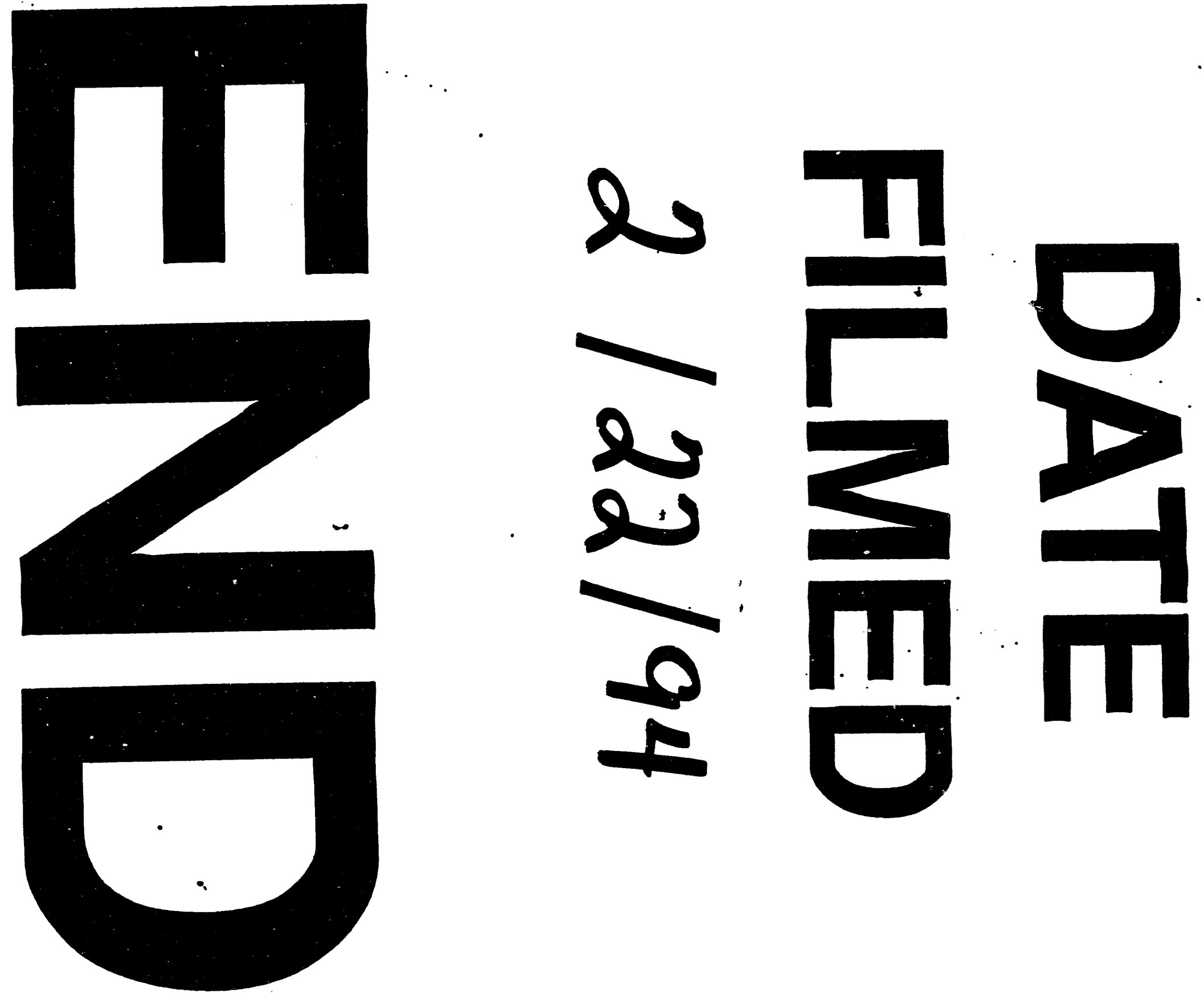